\section{La III Conferencia Internacional Latinoamericanista en la Facultad de Ciencias Políticas de la Universidad Maria Curie-Skłodowska, 21-22 de noviembre de 2018, Lublin, Polonia}

\author{
The 3rd International Latin American Conference at the \\ Faculty of Political Science of Maria Curie-Skłodowska \\ University, November 21-22, 2018, \\ Lublin, Poland
}

Del 21 al 22 de noviembre de 2018, tuvo lugar la III Conferencia Internacional Latinoamericanista, organizada en la Facultad de Ciencias Políticas de la Universidad Maria Curie-Skłodowska por la Profa. Dra. Katarzyna Krzywicka, politóloga y latinoamericanista, fundadora y editora en jefe de la revista científica Anuario Latinoamericano - Ciencias Políticas y Relaciones Internacionales y la Academia Polaca de Ciencias - Sección de Lublin.

El evento tuvo lugar en Lublin con motivo del quinto aniversario de la revista Anuario Latinoamericano - Ciencias Políticas y Relaciones Internacionales y del vigésimo quinto aniversario de la Facultad de Ciencias Políticas de la Universidad Maria Curie-Skłodowska. La conferencia se celebró bajo el patrocinio honorífico de su Rector Magnífico de la UMCS, Prof. Dr. Stanisław Michałowski, el presidente de la Ciudad de Lublin, Dr. Krzysztof Żuk, Su Excelencia la Sra. Embajadora de la República de Argentina en Polonia Ana María Ramírez, Su Excelencia el Sr. Embajador Extraordinario y Plenipotenciario de la República de Cuba en Polonia Jorge Martí Martínez, Su Excelencia el Sr. Embajador de México en Polonia Alejandro Negrín, Su Excelencia el Sr. Embajador de la República de Panamá en Polonia Enrique Antonio Zarak Linares, Su Excelencia el Sr. Embajador del Perú en Polonia Alberto Salas Barahona, Su Excelencia el Sr. Embajador de Uruguay en Polonia Pablo Scheiner, Su Excelencia el Sr. Embajador Extraordinario y Plenipotenciario de la República Bolivariana de Venezuela en Polonia Luis Gómez Urdaneta.

El objetivo de los organizadores de la III Conferencia Internacional Latinoamericanista fue crear un foro de debate para el intercambio de opiniones, ideas y resultados de investigaciones sobre los condicionamientos, la natura-
Anuario Latinoamericano Ciencias Políticas

y Relaciones Internacionales

vol. 7, 2019

pp. 357-359

DOI: 10.17951/al.2019.7.357-359 
leza y el cambio de la posición y el papel de América Latina y el Caribe como la región de las relaciones internacionales en el siglo XXI. Durante la Conferencia, se celebró un debate sobre los siguientes temas:

- los condicionamientos, desafíos y amenazas a la estabilidad geopolítica y geoeconómica de la región;

- las formas de cooperación política y económica a nivel regional e interregional;

- la posición y el papel de los sujetos estatales y no estatales de las relaciones internacionales;

- la naturaleza y la especificidad del liderazgo regional;

- la naturaleza y la especificidad de las transformaciones en los sistemas políticos;

- la especificidad e importancia de los conflictos sociales;

- la especificidad e importancia de las amenazas a la seguridad;

- los conceptos y las estrategias regionales para combatir el crimen organizado.

En la Conferencia participaron politólogos de varios centros de investigación polacos y extranjeros. Durante las sesiones plenarias, los científicos de Argentina, Brasil, Colombia, México, Alemania, España, Gran Bretaña, la República Checa, Lituania y Polonia impartieron ponencias en español. El evento demuestra el alto renombre internacional de los estudios latinoamericanistas en el campo de las ciencias políticas llevados a cabo sistemáticamente en la facultad de Ciencias Políticas de la UMCS.

La III Conferencia Internacional Latinoamericanista fue una de la serie de encuentros científicos que se iniciaron en 2013 en Przemyśl, donde se celebró la I Conferencia Internacional Latinoamericanista sobre el tema: América Latina frente a las transformaciones geopolíticas y nuevas amenazas. La conferencia fue organizada por la Prof. Dra. Katarzyna Krzywicka del Departamento de Relaciones Internacionales de la Facultad de Ciencias Políticas de la UMCS en colaboración con el Dr. Paweł Trefler del Instituto de Relaciones Internacionales de la Escuela Superior Estatal de Europa Oriental en Przemyśl. En 2015, se llevó a cabo la II Conferencia Internacional Latinoamericanista sobre el tema: Las relaciones entre politica y religión en América Latina - determinantes y nuevos paradigmas. Las iniciadoras y organizadoras de este evento, que tuvo lugar en Lublin, fueron la Prof. Dra. Katarzyna Krzywicka del Departamento de Relaciones Internacionales de la Facultad de Ciencias Políticas de la UMCS y la Dra. Renata Siuda-Ambroziak del Centro de Estudios Latinoamericanos de la Universidad de Varsovia. La conferencia fue coorganizada por el Comité de Ciencias Políticas y Relaciones Internacionales de la Academia Polaca de Ciencias - Sección de Lublin.

Las conferencias organizadas cíclicamente son un foro reconocido por los investigadores para el debate interdisciplinario e internacional sobre América Latina y el Caribe y contribuyen al desarrollo y la promoción 
de la investigación sobre esta región en el campo de las ciencias políticas, inscribiéndose en las actividades de la Facultad de Ciencias Políticas y Periodismo de la Universidad Maria Curie-Skłodowska para la internacionalización de la ciencia.

Katarzyna Krzywicka

Facultad de Ciencias Políticas y Periodismo

Universidad Maria Curie-Skłodowska Lublin, Polonia

$\triangle$ katarzyna.krzywicka@umcs.edu.pl https://orcid.org/0000-0001-5623-5384
Anuario Latinoamericano

Ciencias Políticas

y Relaciones Internacionales

vol. 7, 2019

pp. 357-359

DOI: 10.17951/al.2019.7.357-359 